\title{
Clinical and translational implications of the caveolin gene family: lessons from mouse models and human genetic disorders
}

\author{
Isabelle Mercier ${ }^{1,2,3}$, Jean-Francois Jasmin 1,2,3 Stephanos Pavlides $^{1,2,3}$, Carlo Minetti ${ }^{4}$, Neal Flomenberg ${ }^{1,2,3}$, \\ Richard G Pestell ${ }^{1,2,3}$, Philippe G Frank ${ }^{1,2,3}$, Federica Sotgia ${ }^{1,2,3,4}$ and Michael P Lisanti ${ }^{1,2,3,4}$
}

Here we review the clinical and translational implications of the caveolin gene family for understanding the pathogenesis of human diseases, including breast and prostate cancers, pulmonary hypertension, cardiomyopathy, diabetes, and muscular dystrophy. Detailed phenotypic analysis of caveolin knockout mice has served to highlight the crucial role of a caveolin deficiency in the pathogenesis of many human disease processes. Mutations in the human caveolin genes are associated with a number of established genetic disorders (such as breast cancer, lipodystrophy, muscular dystrophy, and cardiomyopathy), making the caveolins important and novel targets for drug development. The implementation of new strategies for caveolin replacement therapy-including caveolin mimetic peptides-is ongoing.

Laboratory Investigation (2009) 89, 614-623; doi:10.1038/labinvest.2009.23; published online 30 March 2009

KEYWORDS: caveolae; caveolins; human disease pathogenesis; mouse animal models

Caveolins are the signature proteins of specialized invaginations of the plasma membrane, named caveolae, that function to regulate signal transduction within the cell. Three members of the caveolin family have been identified, caveolin-1 (Cav-1), -2 (Cav-2), and -3 (Cav-3). Cav-1 and -2 are coexpressed in a wide range of tissues, whereas Cav-3 is muscle specific. The generation of caveolin null mice has demonstrated clear functions for the caveolin proteins in mammalian physiology. Cav-1 null mice present several pathological phenotypes, suggesting that Cav-1 has pleiotropic functions in various organs. Cav-1 null mice show increased susceptibility towards the development of epidermal and mammary tumors, but exhibit decreased tumor formation in the prostate, demonstrating that Cav-1 behaves as a tumor suppressor or a tumor promoter depending on the cellular context. Moreover, several other phenotypes of Cav-1 null mice indicate that Cav-1 is important in the regulation of insulin signaling, and in pulmonary and cardiac function.

Cav-2 null mice reveal unique functions of Cav-2 in the lung and in the skeletal muscle. Indeed, Cav- 2 null mice show lung defects with increased alveolar septal thickness and fibrosis, and exhibit a peculiar skeletal muscle phenotype, with tubular aggregate formation and mitochondrial proliferation. Cav-3 null mice exhibit pathological changes in the skeletal muscle and the heart, and show an unexpected metabolic phenotype, with increased adiposity and insulin resistance.

Importantly, data from human samples confirm that caveolins are involved in human pathology. Mutations in the Cav-1 gene are found in breast cancer as well as in oral squamous-cell carcinomas. Cav-1 mutations are associated exclusively with estrogen receptor (ER- $\alpha$ )-positive breast tumors, suggesting that Cav-1 normally regulates ER expression and signaling. Mutations in the Cav-3 gene are detected in a wide spectrum of skeletal muscle disorders, including limb girdle muscular dystrophy, distal myopathy, idiopathic hyperCKemia, rippling muscle disease, as well as in cardiac pathologies such as familial hypertrophic cardiomyopathy, long-QT congenital syndrome (LQTS), and sudden infant death syndrome (SIDS).

Thus, modulation of caveolin expression may represent a novel therapeutic approach for the treatment of a number

\footnotetext{
'Department of Cancer Biology, Kimmel Cancer Center, Thomas Jefferson University, Philadelphia, PA, USA; '²epartment of Medical Oncology, Kimmel Cancer Center, Thomas Jefferson University, Philadelphia, PA, USA; ${ }^{3}$ Stem Cell Biology and Regenerative Medicine Center, Thomas Jefferson University, Philadelphia, PA, USA and ${ }^{4}$ Muscular and Neurodegenerative Disease Unit, University of Genoa and G Gaslini Pediatric Institute, Genoa, Italy

Correspondence: Dr F Sotgia or Dr MP Lisanti, Department of Cancer Biology, Kimmel Cancer Center, Thomas Jefferson University, 233 South 10th Street, Philadelphia, PA 19107, USA.

E-mails: federica.sotgia@jefferson.edu and michael.lisanti@kimmelcancercenter.org

Received 13 January 2009; accepted 24 January 2009
} 
of pathological conditions. Preliminary studies have shown that a Cav-1 mimetic peptide may be successfully used for the treatment of cancer and of pulmonary hypertension $(\mathrm{PH})$. More studies will be required to evaluate the possibility of using Cav-1 mimetic peptides in other pathological contexts.

\section{CAVEOLAE AND THE CAVEOLIN GENE FAMILY}

Caveolae are $50-100 \mathrm{~nm} \Omega$-shaped invaginations of the plasma membrane. Owing to their high content of cholesterol, glycosphingolipids, and sphingomyelin, caveolae are considered a specialized subset of detergent-insoluble plasma membrane microdomains, named lipid rafts. ${ }^{1}$ The signature proteins of caveolae are a family of proteins called caveolins. ${ }^{2}$ Structurally, the formation of caveolae requires the capability of caveolin to bind cholesterol and to oligomerize (Figure 1). ${ }^{3-5}$ Three members of the caveolin family have been discovered so far.
Cav-1 is widely expressed and is most abundant in adipocytes, fibroblasts, endothelial cells, as well as epithelial cells such as mammary epithelial cells and type I pneumocytes. ${ }^{6}$ Cav- 1 is essential for caveolae formation, and Cav-1 expression levels correlate with caveolae numbers. ${ }^{7,8}$ Cav-2 is expressed in the same cell types as Cav-1. ${ }^{9,10}$ Cav- 3 is the muscle-specific family member and is mainly found in heart, skeletal muscle, as well as smooth muscle cells (SMC). ${ }^{11}$ Caveolins are more than just caveolae-associated proteins. They help drive the formation of a microenvironment to compartmentalize several signaling molecules, thereby facilitating the cross talk between different signaling pathways. ${ }^{12}$ The caveolin-scaffolding domain (CSD) serves as a docking site for the binding and tonic inhibition of several classes of signaling molecules belonging to proproliferative and prosurvival pathways. Thus, deregulation of caveolin expression and function is involved in many pathological conditions. The physiological implications of caveolins

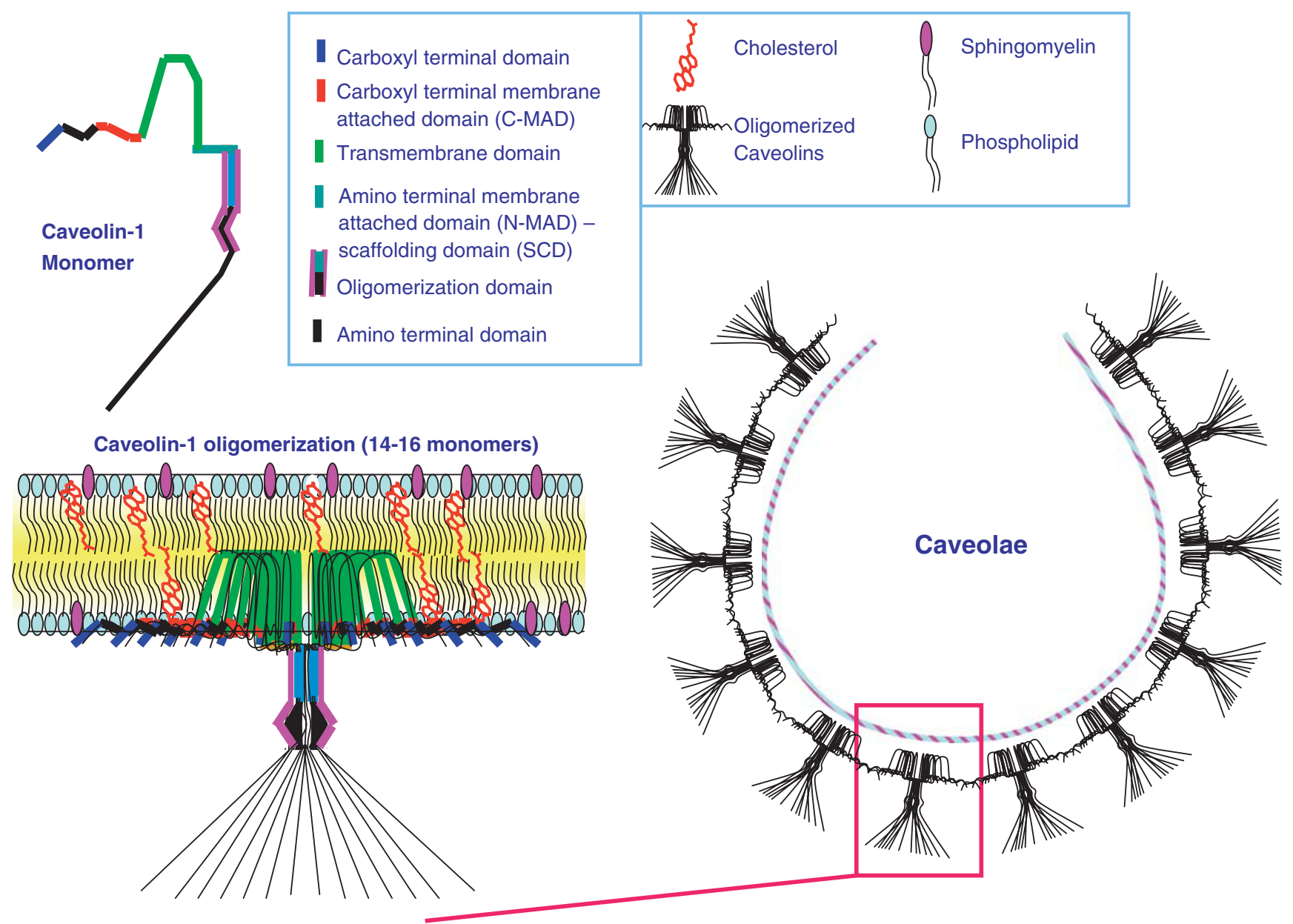

Figure 1 Caveolin domain organization, membrane topology, oligomerization, and caveolar assembly. This diagram summarizes the domain organization of a caveolin-1 monomer, its self-oligomerization into caveolar assembly units, and the integration of these assembly units into a caveolar membrane domain. The cytoplasmic surface of the caveolar coat provides an 'integrated scaffold' onto which various classes of signaling molecules can assemble at the plasma membrane, such as G proteins, Src-family tyrosine kinases, endothelial nitric oxide synthase (eNOS), and components of the Ras-p42/44-MAP kinase cascade. Caveolae organelles also function as docking sites for many different classes of cell-surface receptors, including G-protein-coupled receptors, cytokine receptors, and receptor tyrosine kinases. 
became evident with the generation of null $(-/-)$ mice for each caveolin.

\section{CAV-1 IN TUMOR BIOLOGY: IS CAV-1 A TUMOR SUPPRESSOR, AN ONCONGENE, OR BOTH?}

Several lines of evidence indicate that Cav-1 may act as a tumor suppressor or a tumor promoter depending on the cell type. Cav-1 expression is downregulated in NIH-3T3 cells transformed with various oncogenes such as H-Ras (G12V), Bcr-Abl, and v-Abl. ${ }^{13}$ In soft agar, the anchorageindependent growth of transformed cells can be reversed by Cav-1 re-expression. ${ }^{14,15}$ In NIH-3T3 cells, antisensemediated downregulation of endogenous Cav-1 induces anchorage-independent growth, promotes tumor formation in nude mice with hyperactivation of the MAP kinase pathway. ${ }^{16}$ Importantly, loss of Cav-1 in mice was shown to promote cellular growth in several contexts, including the mammary gland and the skin. For example, although the ablation of Cav-1 is not sufficient to induce spontaneous tumor formation, Cav-1 null mammary glands display cellular hyperplasia, and accelerated mammary gland development during pregnancy. ${ }^{17,18}$ In the MMTV-PyMT (mouse mammary tumor virus-polyoma middle $\mathrm{T}$ antigen) mouse model background, loss of Cav-1 accelerates dysplastic lesion formation, promotes premature development of mammary tumors, and increases metastatic potential. ${ }^{19,20}$ In addition, the combined loss of INK4a, a tumor suppressor, and Cav-1 leads to severe mammary hyperplasia with increased side branching and fibrosis. ${ }^{21}$ In the skin, Cav-1(-/ -) mice demonstrate hypersensitivity to carcinogen-induced epidermal tumors. Following 16 weeks of treatment with the carcinogen DMBA, Cav-1(-/-) null mice show very significant increases in tumor incidence, tumor area, and tumor number per mouse when compared to wild-type (WT) counterparts. ${ }^{22}$ Mechanistically, in the mammary gland and in the skin, Cav-1 is thought to inhibit proliferation and cellular growth. Indeed, in the context of Cav-1 genetic ablation, carcinogen-induced epidermal tumors and oncogene-induced mammary tumors show hyperactivation of the mitogenic p42/44-MAP kinase pathway, with increased levels of cyclin D1. ${ }^{20,22}$

However, Cav-1 does not behave as a tumor suppressor in all cellular contexts. A growing body of evidence derived from cellular, mouse, and human studies clearly indicates that Cav-1 acts as a tumor promoter in other organs, such as the prostate. In the TRAMP (transgenic adenocarcinoma of mouse prostate) mouse model of prostate cancer, Cav-1 expression is increased when compared to the normal prostate epithelium. ${ }^{23}$ Genetic ablation of Cav-1 in TRAMP mice decreases incidence of prostate tumors at 28 weeks of age and reduces metastasis to regional lymph node and to distant organs, such as the lungs. ${ }^{23}$ In patients with prostate cancer, Cav-1 expression is increased in $13 \%$ of well-differentiated tumors, $24 \%$ of moderately differentiated tumors, and $39 \%$ of poorly differentiated tumors. ${ }^{24}$ These results suggest that
Cav-1 overexpression in prostate cancer cells correlates with tumor progression. ${ }^{24}$ Other studies have shown that high levels of Cav-1 are associated with high Gleason's score, reduced survival, and poor prognosis in prostate cancer. ${ }^{25,26}$ Finally, a higher incidence of Cav-1 positivity is observed in metastatic lesions and metastasis-derived cell lines, as compared to primary tumors and primary tumor-derived cell lines, respectively. ${ }^{27}$

In the mammary gland and skin, Cav-1 negatively regulates proliferation. However, the antiapoptotic properties of Cav-1 seem to contribute to the development of prostate cancer. Prostate tumors derived from TRAMP/Cav-1 null mice exhibit increased apoptosis as assessed by TUNEL staining, with increased levels of prostate apoptosis response factor-4 (PAR-4) and PTEN. ${ }^{23}$ However, the function of Cav-1 in apoptosis in other cell types still remains largely unexplored and highly debated. In prostate cancer cells, it is believed that Cav-1 can shift from its conventional membrane-bound position to a secreted form outside the cell. Indeed, Cav-1 has been detected in the serum of patients with prostate cancer. ${ }^{28}$ It was also found that the secreted form of Cav-1 is bioactive as it could promote cell survival. ${ }^{28}$ The phosphorylation of Cav-1 on serine 80 seems to be involved in the conversion of Cav-1 from a membrane protein to a secreted form. ${ }^{29}$

Table 1 summarizes the main phenotypes of Cav-1(-/-) mice and their implications in different human pathologies.

\section{CAV-1 AND ADULT STEM CELLS}

Studies have shown that Cav-1 may normally regulate the proper differentiation of stem/progenitor cell populations in organs, such as the skin, the mammary gland, and the intestine, that are physiologically subjected to constant selfrenewal (Figure 2). For example, Cav-1 deficiency leads to an amplification of an adult mammary stem cell population, both in vivo and in vitro. The expression of stem cell markers, such as Sca-1 and keratin 6, is greatly increased in the hyperplastic mammary ducts of Cav-1-deficient mice, as well as in 3D cultures of Cav-1(-I-) primary mammary epithelial cells. Such an amplification of progenitor cells is functionally associated with the abnormal presence of myoepithelial cells in the hyperplastic lesions of Cav-1-deficient mammary glands. ${ }^{32}$

In addition, genetic ablation of Cav-1 induces an abnormal amplification of small intestine crypt stem cells, resulting in increased susceptibility to $\gamma$-radiation. Cav-1 null small intestine crypt stem cells display higher proliferation rates, as compared to WT controls. Because of its fast renewing nature, the small intestine constitutes one of the main targets of radiation. After $\gamma$-radiation exposure, Cav-1-deficient mice display a decreased survival rate, as compared to WT mice. ${ }^{30}$ Mechanistically, Wnt/ $\beta$-catenin signaling, which normally controls stem cell self-renewal, is upregulated in Cav-1 null mammary and crypt stem cells. The longevity and slowdividing properties of stem cells facilitate the accumulation 
Table 1 Phenotypes of Cav-1 null mice and their implications in human pathologies

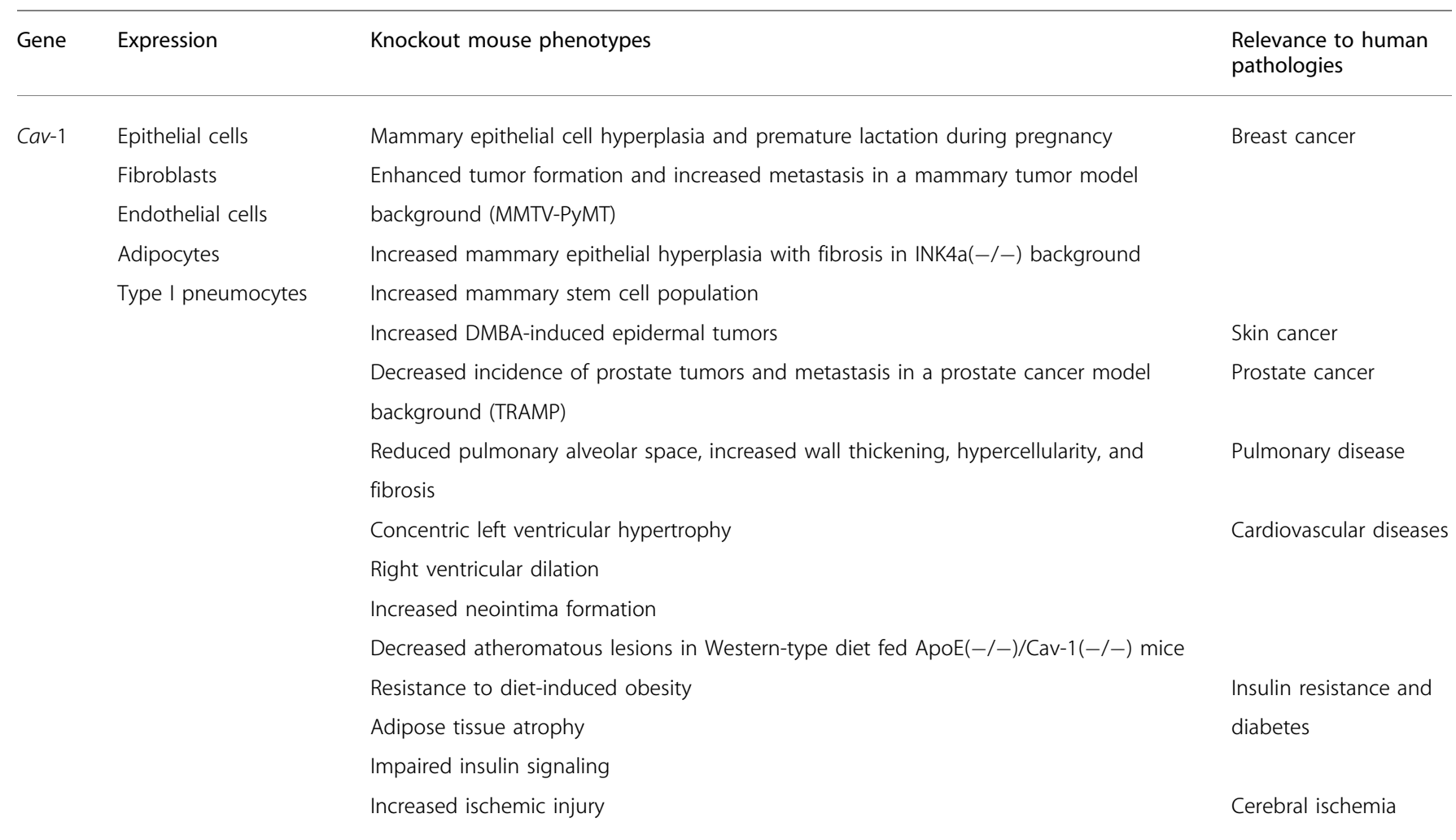

MMTV-PyMT, mouse mammary tumor virus-polyoma middle T antigen; TRAMP, transgenic adenocarcinoma of mouse prostate

of genetic alterations and render progenitor cells likely precursors of malignant derivatives. As such, loss of Cav-1 may induce the accumulation of stem cells, and this event may be an initiating factor during tumorigenesis.

\section{CAV-1: INSULIN SIGNALING, PULMONARY AND CARDIAC FUNCTION, AND ISCHEMIA}

The analysis of Cav-1(-/-) mice has highlighted how the loss of Cav-1 function may lead to a number of important pathological conditions. In addition to its involvement in breast, skin, and prostate cancer, Cav-1 is also important in diabetes, lung and heart diseases, and ischemia (Table 1).

\section{Cav-1, Insulin Signaling, and Diabetes}

Cav-1(-/-) mice show resistance to diet-induced obesity, and display adipose tissue atrophy. ${ }^{33}$ Metabolically, plasma levels of insulin and glucose are normal in Cav-1 null mice. ${ }^{33}$ However, an insulin tolerance test revealed abnormally low glucose uptake in young Cav-1(-/-) mice, suggestive of impaired insulin signaling. ${ }^{34}$ This defect in glucose uptake is due to a severe deficiency of insulin receptor protein expression in Cav-1(-/-) adipose tissue. ${ }^{34}$ In direct support of these findings, Cav-1 null adipose tissue displays decreased insulin signaling, as assessed by phosphorylation of insulin receptor and its downstream targets. ${ }^{34}$ Although loss of Cav1 is not sufficient to induce diabetes, it may function as a predisposing factor for the development of insulin resistance in humans.

\section{Cav-1 and Pulmonary Function}

Cav-1 is highly expressed in the lung, and is found in several pulmonary cell types, including endothelial cells and pneumocytes. Histological analysis of Cav-1 null mice reveals a deeply modified lung morphology with reduced alveolar spaces, increased wall thickening, fibrosis, and hypercellularity. ${ }^{35,36}$ In addition, Cav-1 null mice develop PH. ${ }^{37,38} \mathrm{Re}$ duced Cav-1 levels in the lung have been documented in several animal models of $\mathrm{PH}$ and in patients with severe $\mathrm{PH}$. These findings may have important implications for understanding human respiratory pathologies, such as $\mathrm{PH}$, fibrosis, as well as acute respiratory syndrome.

\section{Cav-1 and Cardiovascular Function}

Cav-1 is implicated in several cardiovascular pathologies, including cardiac hypertrophy, neointima formation and atherosclerosis. Cardiac hypertrophy is a critical pathology leading to heart failure. Cav-1(-/-) mice show progressive concentric left ventricular hypertrophy, as well as right ventricular dilation. ${ }^{37,39}$ Cav-1 expression is restricted to the supporting cells of the heart, such as fibroblasts and endothelial cells. Excessive activation of the Ras-p42/44-MAP kinase cascade in $\mathrm{Cav}-1(-/-)$ cardiac fibroblasts is considered one of the upstream key factors promoting 

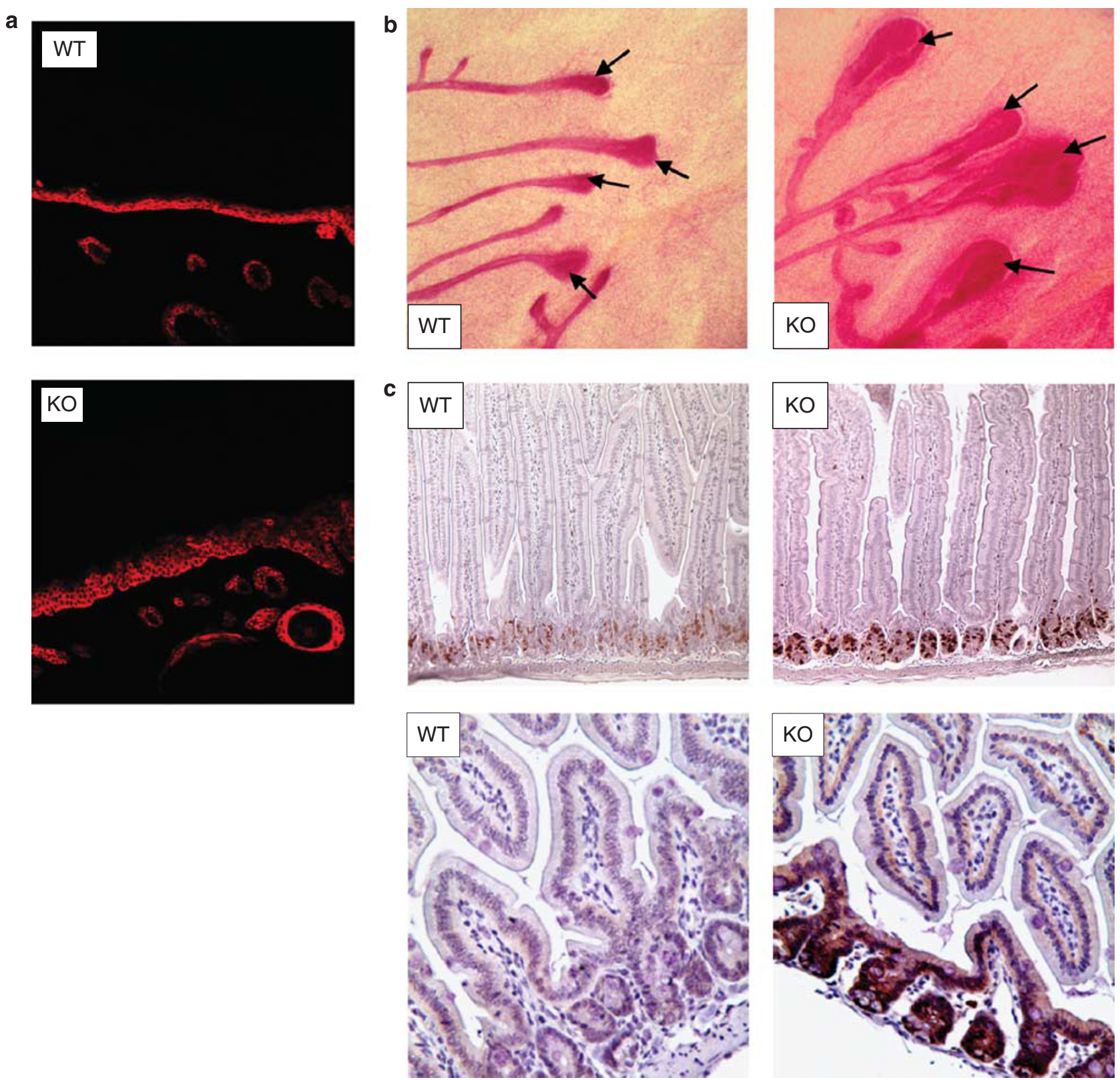

Figure 2 Loss of Cav-1 increases the adult epithelial stem cell compartment. (a) Skin. After DMBA treatment, Cav-1(-/-) mice show an expansion of the basal keratinocyte cell layer in the skin, as marked by immunostaining with anti-keratin-14 lgG. (b) Mammary Gland. Cav-1(-/-) mice show an increase in the size of terminal end buds (TEBs), the site of mammary stem/progenitor cells during adult mammary gland development. Ducts and TEBs are stained red with Carmine dye. (c) Gl tract. The intestinal crypt stem cells from Cav-1(-/-) mice show increases in both proliferation (BrdU incorporation; upper panel)

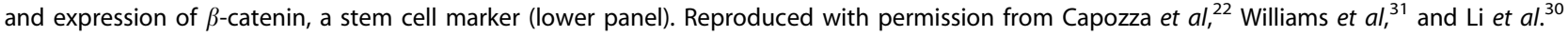

hypertrophy and fibrosis in the adjacent myocytes. ${ }^{40}$ Notably, Cav-1(-/-) cardiac fibroblasts exhibit p42/44 MAP kinase hyperactivation when compared to WT fibroblasts, ${ }^{39}$ suggesting that the hypertrophy of Cav-1 null hearts occurs through a paracrine mechanism.

Neointimal hyperplasia is the principal cause for clinical failures in angioplasty and is a critical component of restenosis. During the development of neointimal hyperplasia, the arterial wall thickens and the lumen narrows as a consequence of SMC accumulation and proliferation in the intima. ${ }^{41,42}$ Genetic ablation of Cav-1 in mice facilitates SMC proliferation and neointima formation. At 4 weeks after ligation, Cav-1(-/-) carotid arteries showed significantly more neointimal hyperplasia with subtotal luminal occlusion, as compared to WT mice. Mechanistically, the development of neointimal hyperplasia in Cav-1(-I-) mice is mediated by elevated levels of phospho-p42/44 MAP kinase and cyclin D $1{ }^{43}$ 
Atherosclerosis is characterized by the accumulation of modified lipoproteins in the subendothelial space followed by the recruitment and proliferation of monocytes/macrophages and SMC. Genetic ablation of Cav-1 in mice confers protection against atherosclerosis. In the apolipoprotein-Edeficient (ApoE-/-) atherogenic mouse model background, loss of Cav-1 prevents the development of aortic atheromas, with an $\sim 70 \%$ reduction in atherosclerotic lesion area. Mechanistically, loss of Cav-1 is associated with the downregulation of proatherogenic molecules, namely CD36 and vascular cell adhesion molecule-1 (VCAM-1). ${ }^{44}$

Thus, Cav-1(-/-) mice are more sensitive to the development of neointimal hyperplasia (luminal narrowing), but are strongly resistant to the development of atheromas, clearly demonstrating the different pathophysiology of subendothelial $v s$ mural narrowing of the arterial lumina.

\section{Cav-1 and Ischemia}

Recent studies have directly addressed the functional role of Cav-1 in ischemic injury. First, Cav-1 ablation in mice was shown to promote ischemic injury in a model of hindlimb ischemia. ${ }^{45}$ Similarly, in a model of cerebral artery occlusion, Cav-1 null mice display a significant increase in the volume of cerebral infarcts, as compared to WT mice. Mechanistically, Cav-1 null ischemic brains exhibited decreased proliferation of endothelial cells and an elevated apoptotic index, as compared to WT counterparts. ${ }^{46}$ Ischemic preconditioning has previously been shown to increase the cardiac phosphorylation of Cav-1 and SRC in mice subjected to myocardial ischemia reperfusion. These interesting observations suggest that phosphorylation of Cav-1 and SRC might have a cardioprotective role in ischemic injuries. Hence, genetic ablation of the Cav-1 gene in mice was shown to attenuate the protective effect of myocardial ischemic preconditioning. ${ }^{47}$

\section{CAVEOLIN-2: PULMONARY AND SKELETAL MUSCLE FUNCTIONS}

Cav-2 requires the presence of Cav-1 for stabilization and membrane targeting, such that in the absence of Cav-1, Cav-2 is retained in the endoplasmic reticulum/Golgi complex and undergoes degradation through a proteasomal pathway. ${ }^{48,49}$ As a consequence, Cav-2 expression is nearly abrogated in Cav-1 null mice. ${ }^{35,36}$ Thus, Cav-2 was considered an 'accessory' protein that functions in conjunction with Cav-1. However, the generation and analysis of Cav-2 null mice revealed unique functions for Cav-2 in the physiology of the lung and of the skeletal muscle. Cav-2 null mice show normal caveolae formation and nearly normal levels of Cav-1 expression. ${ }^{50}$ Cav-2 null lungs show thickened alveolar septa with increased number of endothelial cells. Consequently, Cav-2 null mice show exercise intolerance, suggestive of an impaired gas exchange that is often associated with human pulmonary diseases. ${ }^{50}$ Interestingly, the Cav-2 null lung phenotypes are identical to the ones observed in Cav-1 null mice. ${ }^{35,36}$ Because Cav-2 expression is severely reduced in Cav-1 null mice, a Cav-2 deficiency is considered to be the root cause of this lung disorder.

Cav-2 null mice also exhibit an unexpected skeletal muscle phenotype. Cav-2 null skeletal muscles show peculiar abnormalities, such as tubular aggregate formation, and mitochondrial proliferation/aggregation. In addition, Cav-2 deficiency induces increased numbers of satellite cells, which are skeletal muscle-specific stem/precursor cells. ${ }^{51}$ For a summary of Cav-2 null mice phenotypes and their implications in human pathologies, please refer to Table 2.

\section{CAVEOLIN-3: SKELETAL MUSCLE DISORDERS, HEART DISEASE, AND DIABETES}

Caveolin-3 is the muscle-specific family member, and is necessary for caveolae formation in muscle tissues. Indeed, electron microscopy revealed a lack of caveolae in all striated and cardiac muscle cells of Cav-3 null mice. ${ }^{52,53}$ Cav-3 null skeletal muscle shows signs of mild myopathic changes, such as mononuclear cell infiltration, variable fiber size, and presence of necrosis. These phenotypes are similar to the ones found in a human disease, termed limb-girdle muscular dystrophy (LGMD-1C), which is due to mutations in the Cav-3 gene.

A Cav-3 deficiency also affects cardiac function, with the development of cardiac hypertrophy, dilatation, and reduced fractional shortening at 4 months of age. ${ }^{54}$ Cav-3 null cardiac myocytes show hypertrophy, with cellular infiltrates and progressive interstitial and perivascular fibrosis. Hyperactivation of the Ras-p42/44-MAP kinase pathway is associated with these cardiac phenotypes. ${ }^{54}$

Interestingly, transgenic overexpression of either WT or dominant-negative mutant $\mathrm{Cav}-3$ was shown to induce cardiomyopathy, with cardiac tissue degeneration, and reductions in cardiac functions. ${ }^{55,56}$ These results suggest that maintenance of normal Cav-3 expression levels is essential for proper cardiac function.

Surprisingly, Cav-3 null mice also show an interesting metabolic phenotype. Cav-3 null mice demonstrate increased adiposity and develop insulin resistance, as shown by decreased glucose uptake and reduced glucose metabolic flux in their skeletal muscles. During fasting, Cav-3 null skeletal muscles exhibit normal insulin receptor protein levels. However, insulin stimulation induces a severe reduction in insulin receptor levels in Cav-3 null mice, suggesting that Cav-3 may function to stabilize insulin receptor. These results show that Cav-3 contributes to the regulation of whole body glucose metabolism in vivo and indicates that Cav-3 may be involved in the development of insulin resistance. ${ }^{57,58}$

For a summary of Cav-3 null mouse phenotypes and their implications in human pathologies, please refer to Table 2. 
Table 2 Phenotypes of Cav-2 KO and Cav-3 KO mice and their implications in human pathologies

\begin{tabular}{|c|c|c|c|}
\hline Genes & Expression & Knockout mouse phenotypes & $\begin{array}{l}\text { Relevance to human } \\
\text { pathologies }\end{array}$ \\
\hline \multirow{4}{*}{ Cav-2 } & Epithelial cells & hypercellularity and fibrosis & \\
\hline & Fibroblasts & & \\
\hline & Type I pneumocytes & & \\
\hline & & $\begin{array}{l}\text { Tubular aggregate formation, mitochondrial proliferation, increased } \\
\text { numbers of satellite cells }\end{array}$ & Tubular aggregates \\
\hline Cav-3 & & Increased adiposity, insulin resistance & Diabetes \\
\hline
\end{tabular}

\section{CAVEOLIN MUTATIONS IN HUMAN DISEASE}

Over the past few years, mutations in the caveolin genes have been detected in several types of human diseases, clearly indicating the importance of these proteins for normal human physiology, and demonstrating that dysregulation of caveolin function is a critical factor for the development of human disease.

\section{Cav-3 Mutations}

The first mutations in a caveolin gene were identified a decade ago, when mutations in the Cav-3 gene were found in patients with LGMD-1C. ${ }^{59}$ Since then, several other mutations have been found in patients with skeletal muscle disorders. The spectrum of disease phenotypes associated with Cav-3 mutations is quite variable, ranging from LGMD-1C to idiopathic hyperCKemia, rippling muscle disease, and distal myopathy. For a comprehensive review of Cav-3 and muscle disorders, please consult the GeneReview database available at http://www.genetests.org (search CAV3). Most of the Cav3 mutations are heterozygous and cause a dramatic decrease in Cav-3 expression in skeletal muscle, thus acting in a dominant-negative manner. ${ }^{60}$ Finally, mutations in the Cav-3 gene have been found in familial hypertrophic cardiomyopathy, ${ }^{61}$ in the arrhythmogenic syndrome LQTS, ${ }^{62}$ as well as in SIDS. ${ }^{63}$

\section{Cav-1 Mutations}

Somatic mutations in the Cav-1 gene are involved in human cancer. We and others have shown that a proline to leucine substitution at position $132(\mathrm{P} 132 \mathrm{~L})$ in the Cav-1 gene is found in $16-20 \%$ of breast cancers. ${ }^{64,65}$ This heterozygous mutation acts in a dominant-negative manner and induces the intracellular retention of the normal Cav-1 protein at the level of the ER-Golgi complex. ${ }^{17}$ Other mutations were also found in human breast cancer samples, such as W128stop, Y118H, S136R, I141T, Y148H, and Y148S. ${ }^{65}$ Most interestingly, Cav-1 mutations only correlate with ER- $\alpha(\mathrm{ER}-\alpha)$-positive breast tumors, and are found in up to $35 \%$ ER- $\alpha$ positive tumors. ${ }^{65}$ These results suggest that Cav-1 may regulate ER- $\alpha$ expression. In fact, we have shown that ER- $\alpha$ is dramatically upregulated in the luminal mammary epithelial cells of Cav-1 knockout mice (KO), as compared to their WT counterparts. ${ }^{65}$ Because ER- $\alpha$ expression increases as mammary cell transformation progresses, these results suggest that Cav-1 mutations may be an initiating event in the development of human breast cancers. Thus, screening of patient biopsies for Cav-1 mutations could become a routine analysis as a preventive measure to detect estrogen-dependent breast cancer at an early stage. These findings provide new insights into the regulation of ER- $\alpha$ in breast cancer. Finally, mutations and abnormal expression of Cav-1 have been identified in human oral squamous-cell carcinomas. ${ }^{66}$

Recently, a homozygous mutation in the Cav-1 gene has been detected in Berardinelli-Seip congenital lipodystrophy, a rare genetic disorder characterized by near absence of adipose tissue, severe dyslipidemia, and insulin resistance. This mutation induces a complete loss of Cav- 1 expression in skin fibroblasts. ${ }^{67}$ These findings provide human genetic evidence to directly support a critical role for Cav-1 in regulation of adipocyte function and insulin signaling. Additional heterozygous Cav-1 mutations have now been observed in patients with atypical partial lipodystrophy and hypertriglyceridemia. ${ }^{68}$ See Garg and Agarwal, ${ }^{69}$ for a recent review on this subject. 


\section{CAVEOLIN MIMETIC PEPTIDES: A NOVEL THERAPEUTIC STRATEGY FOR HUMAN PATHOLOGIES}

Cav-1 functions as a powerful tumor suppressor in certain types of cancer and its re-expression in tumor cells could potentially become a new therapeutic avenue for the treatment of human cancers. Tumor progression in mice can be blocked by the administration of a cell-permeable peptide, containing the homeodomain of the antennapedia (penetratin) coupled to the Cav-1 scaffolding domain. ${ }^{70}$ After subcutaneous implantation of Lewis lung carcinoma cells (LLC), the injection of the CSD peptide reduced tumor size and tumor vascular permeability, and increased tumor necrosis, suggesting that Cav-1 prevents tumorigenesis by affecting tumor blood supply. ${ }^{70}$ Similar experiments in WT and Cav-1(-I-) mice further demonstrated the involvement of Cav-1 in vascular permeability and tumor development. In Cav-1 KO mice, LLC-derived tumors showed significantly higher growth rates, with increased angiogenesis and decreased apoptosis than tumors implanted in WT hosts. Most interestingly, administration of CSD peptide was able to reverse tumor hyperpermeability as well as to attenuate the increased tumor growth. ${ }^{71}$

Therapeutic administration of the Cav-1 scaffolding domain peptide has been used in other experimental models. Indeed, administration of CSD peptide has been successfully used to prevent the development of $\mathrm{PH}$, right ventricular hypertrophy, and pulmonary artery medial hypertrophy in a monocrotaline-induced $\mathrm{PH}$ rat model. ${ }^{72}$ Administration of CSD peptide to monocrotaline-treated rats significantly prevented $\mathrm{PH}$ and normalized pulmonary artery medial hypertrophy and right ventricular hypertrophy. ${ }^{72}$ Finally, in an experimental mouse model of inflammation, the administration of the CSD peptide has also been shown to decrease inflammation, reduce edema formation and vascular permeability. ${ }^{73}$ Thus, the administration of Cav-1 peptide mimetics might become a novel alternative treatment for cancer as well as $\mathrm{PH}$ patients.

\section{FUTURE DIRECTIONS: ROLE OF CAVEOLINS IN THE CANCER STROMA}

Normal epithelial cells are often surrounded by fibroblasts that serve mainly as support to protect the tissue from damage. Fibroblasts can proliferate and secrete extracellular matrix (ECM) proteins as a response to injury. Once the wound-healing process is complete, they undergo apoptosis and the ECM production lessens. Several lines of evidence now suggest that stromal fibroblasts become 'activated' and have a very dynamic role in tumor initiation and progression. These cancer-associated fibroblasts (CAFs) express smooth muscle actin, have contractile functions, and secrete ECM proteins. Unlike normal fibroblasts involved in wound repair, these CAFs do not undergo spontaneous apoptosis, rather they remain activated and hyperproliferate. Studies suggest the recruitment of CAFs is not only a secondary event to tumor initiation, but is very dynamic as CAFs can increase the growth of adjacent epithelial cells through paracrine mechanisms. For a complete review on stromal fibroblasts and cancer please see Kalluri and Zeisberg. ${ }^{74}$ However, very little is known about the mechanism(s) controlling the proliferation of CAFs and their clinical implications in cancer progression and outcome. Recently, it was shown that Cav-1 protein expression is decreased in primary cultures of CAFs isolated from patients with invasive breast cancer and that loss of Cav-1 function might be involved in their hyperproliferation. ${ }^{75}$ Accordingly, treatment of these cells with a cellpermeable Cav-1 mimetic peptide decreased the phosphorylation of retinoblastoma protein (RB) as well as proliferating cell nuclear antigen (PCNA) and MCM7 (minichromosome maintenance) proteins levels, two RB/E2F target proteins. Therefore, caveolin proteins might be important in cancer through their novel 'tumor suppressor' function in the neoplastic stroma (Figure 3).

In accordance with this idea, we have recently shown that loss of stromal Cav-1 is a novel breast cancer biomarker that predicts early disease recurrence, metastasis, survival, and tamoxifen resistance. ${ }^{76}$ For example, lymph-node-positive breast cancer patients showed an $\sim 11.5$-fold reduction in 5 -year progression-free survival in the absence of stromal Cav-1 (80 vs $7 \%$ survival). ${ }^{76}$ Mechanistically, this appears to be related to the idea that the loss of Cav-1 expression in mammary fibroblasts leads to pRB inactivation, increased growth factor secretion, and stromal angiogenesis ${ }^{77,78}$ (Figure 3). As such, breast cancer patients lacking stromal

\section{Cancer-Associated Fibroblast (CAF) Phenotype}

Loss of Stromal Cav-1 Expression

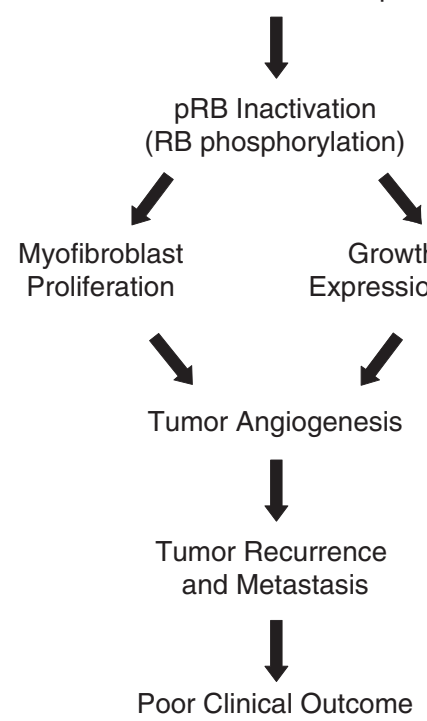

Figure 3 Loss of stromal Cav-1 expression predicts poor clinical outcome in human breast cancer patients. Mechanistically, loss of stromal Cav-1 expression in the tumor microenvironment leads to RB inactivation, increased myofibroblast proliferation, and the secretion of angiogenic growth factors. This, in turn, greatly facilitates tumor recurrence and metastasis, leading to poor clinical outcome. 
Cav-1 might greatly benefit from antiangiogenic therapy, in addition to standard treatment regimens.

Thus, future studies are warranted to explore this novel function for caveolins in the stromal pathogenesis of human cancers.

\section{ACKNOWLEDGEMENTS}

MPL and his laboratory were supported by grants from the $\mathrm{NIH} / \mathrm{NCl}$ (R01-CA-80250; R01-CA-098779; R01-CA-120876), the American Heart Association (AHA), the Muscular Dystrophy Association (MDA), the American Association for Cancer Research (AACR), the Susan G. Komen Breast Cancer Foundation, and the Department of Defense-Breast Cancer Research Program (Synergistic Idea Award). IM was supported by a post-doctoral fellowship from the Susan G Komen Breast Cancer Foundation. PGF was supported by a grant from the WW Smith Charitable Trust, and a Career Catalyst Award from the Susan G Komen Breast Cancer Foundation. FS was supported by grants from the Breast Cancer Alliance, the Elsa U Pardee Foundation, the WW Smith Charitable Trust, and a Research Scholar Grant from the American Cancer Society (ACS). JFJ was supported by a Career Catalyst Award from the Susan G Komen Breast Cancer Foundation. RGP was supported by grants from the NIH/NCI (R01-CA-70896, R01-CA-75503, R01-CA-86072, and R01-CA-107382), and the Dr Ralph and Marian C. Falk Medical Research Trust. The Kimmel Cancer Center was supported by the $\mathrm{NIH} / \mathrm{NCl}$ Cancer Center Core grant P30-CA-56036 (to RGP). This work was funded, in part, under a grant with the Pennsylvania Department of Health (to MPL). The Department specifically disclaims responsibility for any analyses, interpretations, or conclusions.

1. Galbiati F, Razani B, Lisanti MP. Emerging themes in lipid rafts and caveolae. Cell 2001;106:403-411.

2. Rothberg KG, Heuser JE, Donzell WC, et al. Caveolin, a protein component of caveolae membrane coats. Cell 1992;68:673-682.

3. Murata M, Peranen J, Schreiner R, et al. VIP21/caveolin is a cholesterolbinding protein. Proc Natl Acad Sci USA 1995;92:10339-10343.

4. Sargiacomo $M$, Scherer $P E$, Tang Z-L, et al. Oligomeric structure of caveolin: implications for caveolae membrane organization. Proc Natl Acad Sci USA 1995;92:9407-9411.

5. Monier S, Parton RG, Vogel F, et al. VIP21-caveolin, a membrane protein constituent of the caveolar coat, oligomerizes in vivo and in vitro. Mol Biol Cell 1995;6:911-927.

6. Glenney Jr JR, Soppet D. Sequence and expression of caveolin, a protein component of caveolae plasma membrane domains phosphorylated on tyrosine in Rous sarcoma virus-transformed fibroblasts. Proc Natl Acad Sci USA 1992;89:10517-10521.

7. Li S, Song KS, Koh SS, et al. Baculovirus-based expression of mammalian caveolin in Sf21 insect cells. A model system for the biochemical and morphological study of caveolar biogenesis. J Biol Chem 1996;271:28647-28654.

8. Vogel U, Sandvig K, van Deurs B. Expression of caveolin-1 and polarized formation of invaginated caveolae in Caco-2 and MDCK II cells. J Cell Sci 1998;111(Part 6):825-832.

9. Scherer PE, Okamoto T, Chun M, et al. Identification, sequence and expression of caveolin-2 defines a caveolin gene family. Proc Natl Acad Sci USA 1996;93:131-135.

10. Scherer PE, Lewis RY, Volonte $\mathrm{D}$, et al. Cell-type and tissue-specific expression of caveolin-2. Caveolins 1 and 2 co-localize and form a stable hetero-oligomeric complex in vivo. J Biol Chem 1997;272: 29337-29346.

11. Tang Z-L, Scherer PE, Okamoto T, et al. Molecular cloning of caveolin-3, a novel member of the caveolin gene family expressed predominantly in muscle. J Biol Chem 1996;271:2255-2261.

12. Razani B, Woodman SE, Lisanti MP. Caveolae: from cell biology to animal physiology. Pharmacol Rev 2002;54:431-467.

13. Koleske AJ, Baltimore D, Lisanti MP. Reduction of caveolin and caveolae in oncogenically transformed cells. Proc Natl Acad Sci USA 1995;92:1381-1385.

14. Engelman JA, Wykoff CC, Yasuhara S, et al. Recombinant expression of caveolin-1 in oncogenically transformed cells abrogates anchorageindependent growth. J Biol Chem 1997;272:16374-16381.
15. Lee $\mathrm{SW}$, Reimer $\mathrm{CL}$, Oh $\mathrm{P}$, et al. Tumor cell growth inhibition by caveolin re-expression in human breast cancer cells. Oncogene 1998;16:1391-1397.

16. Galbiati F, Volonte D, Engelman JA, et al. Targeted downregulation of caveolin-1 is sufficient to drive cell transformation and hyperactivate the p42/44 MAP kinase cascade. EMBO J 1998;17:6633-6648.

17. Lee H, Park DS, Razani B, et al. Caveolin-1 mutations (P132L and null) and the pathogenesis of breast cancer: caveolin-1 (P132L) behaves in a dominant-negative manner and caveolin-1(-/-) null mice show mammary epithelial cell hyperplasia. Am J Pathol 2002;161:1357-1369.

18. Park DS, Lee H, Frank PG, et al. Caveolin-1-deficient mice show accelerated mammary gland development during pregnancy, premature lactation, and hyperactivation of the Jak-2/STAT5a signaling cascade. Mol Biol Cell 2002;13:3416-3430.

19. Williams TM, Cheung MW, Park DS, et al. Loss of caveolin-1 gene expression accelerates the development of dysplastic mammary lesions in tumor-prone transgenic mice. Mol Biol Cell 2003;14: 1027-1042.

20. Williams TM, Medina F, Badano I, et al. Caveolin-1 gene disruption promotes mammary tumorigenesis and dramatically enhances lung metastasis in vivo role of Cav-1 in cell invasiveness and matrix metalloproteinase (MMP-2/9) secretion. J Biol Chem 2004;279: 51630-51646.

21. Williams TM, Lee H, Cheung MW, et al. Combined loss of INK4a and caveolin-1 synergistically enhances cell proliferation and oncogeneinduced tumorigenesis: role of INK4a/CAV-1 in mammary epithelial cell hyperplasia. J Biol Chem 2004;279:24745-24756.

22. Capozza F, Williams TM, Schubert W, et al. Absence of caveolin-1 sensitizes mouse skin to carcinogen-induced epidermal hyperplasia and tumor formation. Am J Pathol 2003;162:2029-2039.

23. Williams TM, Hassan GS, Li J, et al. Caveolin-1 promotes tumor progression in an autochthonous mouse model of prostate cancer: genetic ablation of Cav-1 delays advanced prostate tumor development in tramp mice. J Biol Chem 2005;280:25134-25145.

24. Yang G, Truong LD, Wheeler TM, et al. Caveolin-1 expression in clinically confined human prostate cancer: a novel prognostic marker. Cancer Res 1999;59:5719-5723.

25. Rajjayabun PH, Garg S, Durkan GC, et al. Caveolin-1 expression is associated with high-grade bladder cancer. Urology 2001;58:811-814.

26. Fong A, Garcia E, Gwynn L, et al. Expression of caveolin-1 and caveolin2 in urothelial carcinoma of the urinary bladder correlates with tumor grade and squamous differentiation. Am J Clin Pathol 2003;120:93-100.

27. Yang G, Truong LD, Timme $T L$, et al. Elevated expression of caveolin is associated with prostate and breast cancer. Clin Cancer Res 1998;4:1873-1880.

28. Tahir SA, Yang G, Ebara S, et al. Secreted caveolin-1 stimulates cell survival/clonal growth and contributes to metastasis in androgeninsensitive prostate cancer. Cancer Res 2001;61:3882-3885.

29. Schlegel A, Arvan P, Lisanti MP. Caveolin-1 binding to endoplasmic reticulum membranes and entry into the regulated secretory pathway are regulated by serine phosphorylation. Protein sorting at the level of the endoplasmic reticulum. J Biol Chem 2001;276:4398-4408.

30. Li J, Hassan GS, Williams TM, et al. Loss of caveolin-1 causes the hyperproliferation of intestinal crypt stem cells, with increased sensitivity to whole body gamma-radiation. Cell Cycle 2005;4:1817-1825.

31. Williams TM, Sotgia $F$, Lee $H$, et al. Stromal and epithelial caveolin-1 both confer a protective effect against mammary hyperplasia and tumorigenesis: caveolin-1 antagonizes cyclin D1 function in mammary epithelial cells. Am J Pathol 2006;169:1784-1801.

32. Sotgia F, Williams TM, Cohen AW, et al. Caveolin-1-deficient mice have an increased mammary stem cell population with upregulation of Wnt/beta-catenin signaling. Cell Cycle 2005;4:1808-1816.

33. Razani B, Combs TP, Wang XB, et al. Caveolin-1-deficient mice are lean, resistant to diet-induced obesity, and show hypertriglyceridemia with adipocyte abnormalities. J Biol Chem 2002;277:8635-8647.

34. Cohen AW, Razani B, Wang XB, et al. Caveolin-1-deficient mice show insulin resistance and defective insulin receptor protein expression in adipose tissue. Am J Physiol Cell Physiol 2003;285:C222-C235.

35. Drab $M$, Verkade $P$, Elger $M$, et al. Loss of caveolae, vascular dysfunction, and pulmonary defects in caveolin-1 gene-disrupted mice. Science 2001;293:2449-2452. 
36. Razani B, Engelman JA, Wang XB, et al. Caveolin-1 null mice are viable but show evidence of hyperproliferative and vascular abnormalities. J Biol Chem 2001;276:38121-38138.

37. Zhao YY, Liu Y, Stan RV, et al. Defects in caveolin-1 cause dilated cardiomyopathy and pulmonary hypertension in knockout mice. Proc Natl Acad Sci USA 2002;99:11375-11380.

38. Jasmin JF, Mercier I, Hnasko R, et al. Lung remodeling and pulmonary hypertension after myocardial infarction: pathogenic role of reduced caveolin expression. Cardiovasc Res 2004;63:747-755.

39. Cohen AW, Park DS, Woodman SE, et al. Caveolin-1 null mice develop cardiac hypertrophy with hyperactivation of p42/44 MAP kinase in cardiac fibroblasts. Am J Physiol Cell Physiol 2003;284:C457-C474.

40. Booz GW, Dostal DE, Baker KM. Paracrine actions of cardiac fibroblasts on cardiomyocytes: implications for the cardiac renin-angiotensin system. Am J Cardiol 1999;83:44H-47H.

41. Ross R. The pathogenesis of atherosclerosis: a perspective for the 1990s. Nature 1993;362:801-809.

42. Kohler TR, Kirkman TR, Kraiss LW, et al. Increased blood flow inhibits neointimal hyperplasia in endothelialized vascular grafts. Circ Res 1991;69:1557-1565.

43. Hassan GS, Jasmin JF, Schubert W, et al. Caveolin-1 deficiency stimulates neointima formation during vascular injury. Biochemistry 2004;43:8312-8321.

44. Frank PG, Lee H, Park DS, et al. Genetic ablation of caveolin-1 confers protection against atherosclerosis. Arterioscler Thromb Vasc Biol 2004;24:98-105.

45. Sonveaux $\mathrm{P}$, Martinive $\mathrm{P}$, DeWever J, et al. Caveolin-1 expression is critical for vascular endothelial growth factor-induced ischemic hindlimb collateralization and nitric oxide-mediated angiogenesis. Circ Res 2004;95:154-161.

46. Jasmin JF, Malhotra S, Singh Dhallu M, et al. Caveolin-1 deficiency increases cerebral ischemic injury. Circ Res 2007;100:721-729.

47. Patel HH, Tsutsumi YM, Head BP, et al. Mechanisms of cardiac protection from ischemia/reperfusion injury: a role for caveolae and caveolin-1. FASEB J 2007;21:1565-1574.

48. Parolini I, Sargiacomo M, Galbiati F, et al. Expression of caveolin-1 is required for the transport of caveolin-2 to the plasma membrane. Retention of caveolin-2 at the level of the Golgi complex. J Biol Chem 1999;274:25718-25725.

49. Mora R, Bonilha VL, Marmorstein A, et al. Caveolin-2 localizes to the Golgi complex but redistributes to plasma membrane, caveolae, and rafts when co-expressed with caveolin-1. J Biol Chem 1999;274: 25708-25717.

50. Razani B, Wang XB, Engelman JA, et al. Caveolin-2-deficient mice show evidence of severe pulmonary dysfunction without disruption of caveolae. Mol Cell Biol 2002;22:2329-2344.

51. Schubert W, Sotgia F, Cohen AW, et al. Caveolin-1(-/-)- and caveolin2(-/-)-deficient mice both display numerous skeletal muscle abnormalities, with tubular aggregate formation. Am J Pathol 2007:170:316-333.

52. Hagiwara Y, Sasaoka T, Araishi K, et al. Caveolin-3 deficiency causes muscle degeneration in mice. Hum Mol Genet 2000;9:3047-3054.

53. Galbiati F, Engelman JA, Volonte D, et al. Caveolin-3 null mice show a loss of caveolae, changes in the microdomain distribution of the dystrophin-glycoprotein complex, and T- tubule abnormalities. J Biol Chem 2001;19:19.

54. Woodman SE, Park DS, Cohen AW, et al. Caveolin-3 knock-out mice develop a progressive cardiomyopathy and show hyperactivation of the p42/44 MAPK cascade. J Biol Chem 2002;277:38988-38997.

55. Aravamudan $B$, Volonte $D$, Ramani $R$, et al. Transgenic overexpression of caveolin-3 in the heart induces a cardiomyopathic phenotype. Hum Mol Genet 2003;12:2777-2788.

56. Ohsawa $Y$, Toko $H$, Katsura $M$, et al. Overexpression of P104L mutant caveolin-3 in mice develops hypertrophic cardiomyopathy with enhanced contractility in association with increased endothelial nitric oxide synthase activity. Hum Mol Genet 2004;13:151-157.

57. Oshikawa J, Otsu K, Toya $Y$, et al. Insulin resistance in skeletal muscles of caveolin-3-null mice. Proc Natl Acad Sci USA 2004;101:12670-12675.
58. Capozza F, Combs TP, Cohen AW, et al. Caveolin-3 knockout mice show increased adiposity and whole body insulin resistance, with ligand-induced insulin receptor instability in skeletal muscle. Am J Physiol Cell Physiol 2005;288:C1317-C1331.

59. Minetti C, Sotgia F, Bruno C, et al. Mutations in the caveolin-3 gene cause autosomal dominant limb-girdle muscular dystrophy. Nat Genet 1998;18:365-368.

60. Galbiati F, Volonte D, Minetti C, et al. Phenotypic behavior of caveolin3 mutations that cause autosomal dominant limb girdle muscular dystrophy (LGMD-1C). Retention of LGMD-1C caveolin-3 mutants within the Golgi complex. J Biol Chem 1999;274:25632-25641.

61. Hayashi T, Arimura T, Ueda K, et al. Identification and functional analysis of a caveolin-3 mutation associated with familial hypertrophic cardiomyopathy. Biochem Biophys Res Commun 2004;313:178-184.

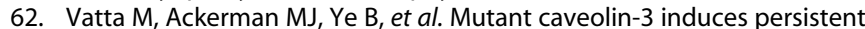
late sodium current and is associated with long-QT syndrome. Circulation 2006;114:2104-2112.

63. Cronk LB, Ye B, Kaku T, et al. Novel mechanism for sudden infant death syndrome: persistent late sodium current secondary to mutations in caveolin-3. Heart Rhythm 2007;4:161-166.

64. Hayashi K, Matsuda S, Machida K, et al. Invasion activating caveolin-1 mutation in human scirrhous breast cancers. Cancer Res 2001;61: 2361-2364.

65. Li T, Sotgia F, Vuolo MA, et al. Caveolin-1 mutations in human breast cancer: functional association with estrogen receptor alpha-positive status. Am J Pathol 2006;168:1998-2013.

66. Han SE, Park KH, Lee G, et al. Mutation and aberrant expression of caveolin-1 in human oral squamous cell carcinomas and oral cancer cell lines. Int J Oncol 2004;24:435-440.

67. Ae Kim C, Delepine M, Boutet E, et al. Association of a homozygous nonsense caveolin-1 mutation with Berardinelli-Seip congenital lipodystrophy. J Clin Endocrinol Metab 2008;93:1129-1134.

68. Cao H, Alston L, Ruschman J, et al. Heterozygous CAV1 frameshift mutations (MIM 601047) in patients with atypical partial lipodystrophy and hypertriglyceridemia. Lipid Health Dis 2008;7:3.

69. Garg A, Agarwal AK. Caveolin-1: a new locus for human lipodystrophy. J Clin Endocrinol Metab 2008;93:1183-1185.

70. Gratton JP, Lin MI, Yu J, et al. Selective inhibition of tumor microvascular permeability by cavtratin blocks tumor progression in mice. Cancer Cell 2003:4:31-39.

71. Lin MI, Yu J, Murata T, et al. Caveolin-1-deficient mice have increased tumor microvascular permeability, angiogenesis, and growth. Cancer Res 2007;67:2849-2856.

72. Jasmin JF, Mercier I, Dupuis J, et al. Short-term administration of a cellpermeable caveolin-1 peptide prevents the development of monocrotaline-induced pulmonary hypertension and right ventricular hypertrophy. Circulation 2006;114:912-920.

73. Bucci M, Gratton JP, Rudic RD, et al. In vivo delivery of the caveolin-1 scaffolding domain inhibits nitric oxide synthesis and reduces inflammation. Nat Med 2000;6:1362-1367.

74. Kalluri R, Zeisberg M. Fibroblasts in cancer. Nat Rev Cancer 2006;6: 392-401.

75. Mercier I, Casimiro MC, Wang C, et al. Human breast cancer-associated fibroblasts (CAFs) show caveolin-1 downregulation and RB tumor suppressor functional inactivation: implications for the response to hormonal therapy. Cancer Biol Ther 2008;7:1212-1225.

76. Witkiewicz AK, Dasgupta A, Sotgia F, et al. An absence of stromal caveolin-1 expression predicts early tumor recurrence and poor clinical outcome in human breast cancers. Am J Pathol 2009, (in press).

77. Sotgia F, Del Galdo F, Casimiro MC, et al. Caveolin-1(-/-) null mammary stromal fibroblasts share characteristics with human breast cancer-associated fibroblasts. Am J Pathol 2009;174:746-761.

78. Mercier I, Casimiro MC, Zhou J, et al. Genetic ablation of caveolin-1 drives estrogen-hypersensitivity and the development of DCIS-like mammary lesions. Am J Pathol 2009;174:1172-1190. 